\title{
Características Quantitativas da Carcaça de Bubalinos de Três Grupos Genéticos Terminados em Confinamento e Abatidos em Diferentes Estádios de Maturidade
}

\author{
André Mendes Jorge ${ }^{1}$, Cristiana Andrighetto ${ }^{2}$, Danilo Domingues Millen ${ }^{3}$, Michel Golfetto \\ Calixto $^{4}$, Anderson Daniel Freitas Vargas $^{5}$
}

\begin{abstract}
RESUMO - Objetivou-se estudar as características quantitativas da carcaça de 36 bubalinos (12 Murrah 12 Jafarabadi e 12 Mediterrâneo), com idade média de 18 meses e peso vivo inicial de $330 \mathrm{~kg}$, terminados em confinamento. Os 12 animais de cada grupo genético foram divididos aleatoriamente em três subgrupos de quatro animais e submetidos aos seguintes tratamentos: Maturidade 1: 400 kg PV ao abate; Maturidade 2: 450 kg PV ao abate; Maturidade 3: 500 kg PV ao abate. Durante o experimento, uma ração única, em que 50\% da MS foi composta por volumoso, foi fornecida, ad libitum, para todos os animais. Após os abates pré-fixados, determinou-se o peso corporal vazio (PCVZ) dos animais pelo somatório das partes integrantes do corpo. Não houve diferença entre grupos genéticos e maturidades, em relação à porcentagem dos cortes dianteiro, paleta, traseiro total e alcatra completa. O rendimento de traseiro especial foi maior nos animais abatidos aos $400 \mathrm{~kg}$ PV e menor naqueles com $500 \mathrm{~kg}$ PV, enquanto o dos animais com $450 \mathrm{~kg}$ PV não diferiu dos demais. O rendimento de ponta-de-agulha, por sua vez, foi maior nos animais com 500 kg PV e menor nos com 400 kg PV. Os valores observados nesses dois pesos de abate não diferiram do obtido nos animais com 450 kg. A produção de carne a partir das raças Murrah, Jafarabadi e Mediterrâneo criadas no Brasil não difere quanto aos rendimentos de carcaça, traseiro, dianteiro e dos principais cortes básicos de interesse comercial.
\end{abstract}

Palavras-chave: búfalos, Jafarabadi, Mediterrâneo, Murrah, pesos de abate, rendimento

\section{Quantitative Carcass Traits of Buffaloes from Three Genetic Groups Finished in Feedlot and Slaughtered at Different Maturities}

\begin{abstract}
This work was conducted to study the quantitative carcass traits of 36 buffaloes (12 Murrah - MUR, 12 Jafarabadi - JAF and 12 Mediterranean - MED) averaging 18 months old and initial body weight (BW) of $330 \mathrm{~kg}$ finished in feedlot. Twelve animals of each genetic group were randomly assigned to three sub-groups (four animals) and distributed to the following treatments: Maturity 1 - slaughter weight at $400 \mathrm{~kg}$ of BW, Maturity 2 - slaughter weight at $450 \mathrm{~kg}$ of BW, or Maturity 3 - slaughter weight at $500 \mathrm{~kg}$ of BW. Animals had free access to a diet containing 50\% of forage (DM basis). After each slaughter empty body weight (EBW) was determined through the sum of body parts. No differences among genetic groups and maturity were observed for yields of hind and forequarters, whole shoulder and whole rump. However, animals slaughtered at $400 \mathrm{~kg}$ of BW had lower yield of beef plate than those slaughtered at $500 \mathrm{~kg}$ of BW while animals on treatment 2 were intermediate. Opposed behavior was observed regarding whole shoulder yield. Production of meat from Murrah, Jafarabadi and Mediterranean did not differ for yields of carcass yield and prime cuts.
\end{abstract}

Key Words: buffaloes, Jafarabadi, Mediterranean, Murrah, slaughter weight, yield

\section{Introdução}

A pecuária de corte atualmente passa por uma reestruturação em que eficiência e competitividade em sistemas de produção sustentados são as metas do setor.

Segundo Vaz et al. (2003), a bubalinocultura de corte deve ser fomentada, pois já conquistou espaço na pecuária de corte, principalmente em razão da rusticidade dos animais, bastante adaptados a solos de baixa fertilidade e a terrenos alagadiços, onde algumas raças bovinas não apresentam a mesma produtividade.
Utilizando-se rações balanceadas em sistemas de confinamento, épossível obter maior ganho diário de peso e redução da idade de abate, que refletem positivamente sobre a qualidade das carcaças e a oferta de carne na entressafra. Nesse contexto, o estudo de características como rendimento, composição e qualidade de carcaça, entre outras, assume grande importância (Jorge, 1999).

O investimento em genética é também uma alternativa para se obter proveito da atividade, gerando animais mais adaptados ao meio, com maior capacidade para ganho de peso e com boas características de carcaça.

\footnotetext{
${ }^{1}$ Prof. Dr. do DPEA/FMVZ/UNESP-Botucatu-SP. Pesquisador CNPq (andrejorge@fmvZ.unesp.br).

${ }^{2}$ Doutoranda em Zootecnia pela FMVZ/UNESP/Botucatu-SP. Bolsista CAPES.

${ }^{3}$ Graduando em Zootecnia da FMVZIUNESP-Botucatu-SP. Bolsista CNPq-PIBIC

${ }^{4}$ Mestre em Zootecnia pela FMVZ/UNESP-Botucatu-SP.

${ }^{5}$ Mestrando em Zootecnia pela FMVZ/UNESP/Botucatu-SP. Bolsista FAPESP.
} 
As pesquisas sobre as características de carcaças de bubalinos criados em diferentes condições de manejo e alimentação no Brasil são ainda escassas e os resultados, às vezes, contraditórios (Jorge et al., 1997a).

Além disso, é imprescindível ao consumidor, em especial o de carne bubalina, que o animal seja abatido ainda jovem. Um dos principais fatores limitantes do consumo de carnes bovina e bubalina é que esse alimento não possui qualidade constante, pois, na maioria das vezes, é proveniente de animais velhos ou de reprodutores descartados dos rebanhos de corte e leiteiro, em razão da idade avançada (Vaz \& Restle, 1998).

Em termos econômicos, é desejável maior rendimento do traseiro especial em relação aos demais cortes, uma vez que nele se encontram as partes nobres da carcaça, que têm maior valor no mercado. A avaliação do rendimento do corte serrote (traseiro especial) e de seus componentes e do costilhar (ponta-de-agulha) é de grande utilidade, visto que esses cortes são utilizados comercializados em grande parte pelos frigoríficos e açougues.

Berg \& Butterfield (1976) afirmam que, em condições normais, e independentemente da raça, o animal apresenta tendência de equilíbrio entre os quartos dianteiro e traseiro e que o sexo dos animais pode ter algum efeito sobre o balanço do dianteiro e traseiro. Machos inteiros, quando atingem certa idade, apresentam o dimorfismo sexual característico, ocasionando maior desenvolvimento do quarto dianteiro (cabeça, pescoço, acém e peito).

Lorenzoni (1984), ao comparar o rendimento de carcaça de animais Nelore, Holandeses, mestiços (1/2 Holandês-Zebu, 3/4 Holandês-Zebu e 5/8 Holandês-Zebu) e búfalos, concluiu que animais Nelore apresentam os maiores valores, provavelmente em razão dos menores pesos de cabeça, pés, couro, rins e trato gastrintestinal, expressos em porcentagem do peso de abate.

Peron et al. (1993), trabalhando com bovinos Nelore (NE), $F_{1}$ Nelore-Chianina (NC), $F_{1}$ NeloreHolandês (NH), F 1 Gir-Holandês (GH) e 3/4 Holandês-Gir (3/4), verificaram que os animais dos grupos genéticos tipicamente de corte (NE e NC) apresentaram maior rendimento de carcaça, com base no peso vivo, que os grupos de mestiços da raça Holandesa. Estes resultados são coerentes com as observações de que os animais mestiços holandeses tendem a apresentar maior tamanho relativo dos órgãos internos que os Nelore e F1 Nelore-Chianina.

Galvão et al. (1991), no entanto, em estudo com animais Nelore, $\mathrm{F}_{1}$ Nelore-Marchigiana e $\mathrm{F}_{1}$ NeloreLimousine abatidos em duas faixa de peso (450 e 500 kg), registraram maior rendimento de carcaça nos animais $\mathrm{F}_{1}$ Nelore-Limousine e menor nos animais Nelore.

Trabalhando com bubalinos Mediterrâneo e bovinos Nelore em diversos sistemas de criação, no estado de São Paulo, Mattos et al. (1997) constataram que os bubalinos mostraram-se bastante precoces, atingindo peso de abate aos 24 meses, em pastagens exclusivas, e praticamente aos 18 meses, quando confinados aos 14 meses, ao passo que bovinos Nelore nascidos na mesma estação de nascimento que bubalinos ( $1^{0}$ semestre), para atingirem peso de abate aos 24 meses, necessitaram permanecer em confinamento a partir dos 16 meses (oito meses confinados).

Jorge et al. (1997a,b) e Jorge \& Fontes (1997), trabalhando com bovinos dos grupos genéticos Nelore, $\mathrm{F}_{1}$ Holandês-Nelore e bimestiços, e bubalinos Mediterrâneo abatidos em diferentes estádios de maturidade fisiológica (peso de abate), observaram que os bubalinos apresentaram menor rendimento de dianteiro e maior de traseiro total, como conseqüência de sua maior proporção de ponta-de-agulha, uma vez que não diferiram dos bovinos quanto ao rendimento de traseiro especial.

Vaz et al. (2003), em pesquisas envolvendo búfalos Mediterrâneo em confinamento, verificaram, em animais alimentados com volumosos à base de cana-deaçúcar ou silagem de milho, valores médios de 37,0; 12,8 e 50,1\%, respectivamente, para rendimentos de dianteiro, de ponta-de-agulha e de traseiro especial, não havendo diferenças entre tipo de alimentação.

Franzolin et al. (1998) e Franzolin \& Silva (2001) avaliaram os efeitos de diferentes níveis de energia ingerida (baixa energia - BE), energia requerida (RE) e alta energia (AE) sobre as características de carcaça de animais Mediterrâneo e observaram rendimentos médios de dianteiro e de ponta-de-agulha na carcaça de 38,4 e 14,1\%, respectivamente, concluindo que os bubalinos possuem bom potencial de produção de carcaça, com bons rendimentos de cortes comerciais quando terminados em confinamento.

Neste trabalho, objetivou-se estudar os efeitos de grupo genético e de estádio de maturidade (peso de abate) sobre as características quantitativas da carcaça de bubalinos terminados em confinamento. 


\section{Material e Métodos}

O experimento foi realizado no Departamento de Produção e Exploração Animal da Faculdade de Medicina Veterinária e Zootecnia, UNESP, em Botucatu, SP, cujas coordenadas geográficas são latitude sul $22^{\circ} 51^{\prime}$ e longitude oeste $48^{\circ} 26^{\prime}$, altitude média 800 m do nível do mar, temperatura média anual $20,2^{\circ} \mathrm{C}$ e precipitação média anual de $1.464 \mathrm{~mm}$.

Foram utilizados 48 bubalinos (16 Murrah - MUR, 16 Jafarabadi - JAF e 16 Mediterrâneo - MED) com média de 18 meses de idade e peso vivo (PV) inicial de $330 \pm 13 \mathrm{~kg}$.

Os animais foram mantidos em confinamento, distribuídos aleatoriamente em baias individuais, com piso concretado, providas de bebedouro e comedouro de cimento. Antes do início do experimento, foram submetidos ao controle de endo e ectoparasitas, identificados com brinco e receberam duas mil unidades internacionais de vitamina $\mathrm{A}$, em razão do uso subseqüente de feno na dieta.

Após o período de adaptação (35 dias), quatro animais de cada grupo genético foram designados por sorteio para o abate e serviram de referência (REF) no estudo do peso inicial de corpo vazio (PCVZ) e do peso da carcaça. Os 12 animais restantes de cada grupo genético foram divididos aleatoriamente em três subgrupos de quatro animais e submetidos aos seguintes tratamentos: Maturidade 1: $400 \mathrm{~kg}$ PV ao abate; Maturidade 2: 450 kg PV ao abate; Maturidade 3: $500 \mathrm{~kg}$ PV ao abate.

Durante o experimento, todos os animais receberam uma ração única, ad libitum, uma vez ao dia, composta por $50 \%$ de feno de coast-cross, na matéria seca, e 50\% de concentrado à base de fubá de milho, uréia e farelo de soja, devidamente suplementado com minerais. A ração foi formulada segundo as normas do NRC (1996) para ganho de peso vivo diário de 1,2 kg.

A duração do período experimental não foi préfixada, uma vez que os animais seriam abatidos assim que atingissem os pesos pré-estabelecidos de 400, 450 ou $500 \mathrm{~kg}$ PV. A cada 28 dias, todos os animais foram pesados e, à medida que se aproximavam do peso de abate pré-estabelecido, eram pesado em intervalos menores, para que fossem ser abatido com o peso previsto. Antes do abate, os animais foram submetidos a jejum de sólidos por 16 horas e encaminhados ao frigorífico para serem abatidos conforme o fluxo operacional.
Após o abate, os pesos de cabeça, pés, couro, trato gastrintestinal vazio, gordura interna, fígado, coração, rins, baço, pulmões, língua, sangue, mesentério, cauda, esôfago, traquéia e aparelho reprodutor foram registrados. As duas meia-carcaças quentes foram pesadas e, posteriormente, resfriadas em câmara fria a $-5^{\circ} \mathrm{C}$, durante 24 horas.

Após o resfriamento, a meia-carcaça direita foi pesada e desossada para determinação do rendimento de cortes cárneos, de traseiro e dianteiro. A porcentagem de cortes comerciais foi obtida em relação ao peso da meia-carcaça direita resfriada e em relação ao peso das porções que o originaram, como o traseiro especial, dianteiro ou ponta-de-agulha.

O peso corporal vazio (PCVZ) dos animais foi calculado somando-se os pesos de carcaça, sangue, cabeça, pés, couro, cauda e vísceras. Relações específicas entre o PCVZ e o PV dos animais-referência (REF) foram determinadas para cada raça e utilizadas para se estimar o peso corporal vazio inicial dos animais experimentais (Maturidade 1: $400 \mathrm{~kg}$ PV ao abate; Maturidade 2: $450 \mathrm{~kg}$ PV ao abate; e Maturidade 3: $500 \mathrm{~kg}$ PV ao abate). O peso corporal vazio final foi determinado de modo semelhante ao adotado para os animais-referência (REF).

Relações específicas entre o peso de carcaça e o peso corporal vazio dos animais-referência (REF) foram utilizadas para se estimar o peso inicial dos animais experimentais (Maturidade 1: $400 \mathrm{~kg}$ PV ao abate; Maturidade 2: 450 kg PV ao abate; e Maturidade 3: $500 \mathrm{~kg}$ PV ao abate).

As análises estatísticas foram realizadas utilizando-se o procedimento GLM (“General Linear Model”) do Sistema de Análise Estatística, SAS (1994), de acordo com o modelo:

$$
\mathrm{Y}_{\mathrm{ijk}}=\mu+\mathrm{GG}_{\mathrm{i}}+\mathrm{PA}_{\mathrm{j}}+(\mathrm{GG} * \mathrm{PA})_{\mathrm{ij}}+\mathrm{E}_{\mathrm{ijk}} \text {, }
$$

em que: $\mathrm{Y}_{\mathrm{ijk}}=$ observação referente ao animal $\mathrm{k}$ do grupo genético i, com peso de abate $\mathrm{j} ; \mu$ = média geral; $\mathrm{GG}_{\mathrm{i}}=$ efeito do grupo genético $\mathrm{i}$, em que $\mathrm{i}=1$ (MUR); 2 (JAF); 3 (MED); $\mathrm{PA}_{\mathrm{j}}=$ efeito do peso de abate j, em que j = 1 (400 kg); 2 (450 kg) e 3 (500 kg); $(\mathrm{GG} * \mathrm{PA})_{\mathrm{ij}}=$ efeito da interação grupo genético i $\mathrm{x}$ peso de abate $\mathrm{j} ; \mathrm{e}_{\mathrm{ijk}}=$ erro aleatório, pressuposto NID $\left(0, \sigma^{2}\right)$.

As médias foram comparadas pelo teste Tukey, a 5\% de probabilidade. 


\section{Resultados e Discussão}

As análises de variância para rendimentos de carcaça e dos cortes dianteiro, paleta e acém completos, traseiro total, traseiro especial, alcatra completa, coxão e ponta-de-agulha comprovaram não haver efeito significativo de interação $(P>0,05)$ entre grupos genéticos (Murrah, Jafarabadi e Mediterrâneo) e maturidades (pesos de abate de 400, 450 e $500 \mathrm{~kg}$ PV) e, portanto, os dois efeitos foram considerados independentes.

Na Tabela 1 são apresentados os rendimentos de carcaça dos cortes básicos dos animais dos diferentes grupos genéticos.

Os valores de rendimento de carcaça em relação ao peso vivo (RPV) obtidos nos animais bubalinos deste estudo confirmam perfeitamente os dados disponíveis na literatura, que indicam rendimentos de carcaça de aproximadamente 53-54\%, o que é considerado bom (Lorenzoni et al., 1984; Müller et al., 1994; Mattos et al., 1997; Jorge et al., 1997a; Jorge \& Fontes, 1997; Franzolin et al., 1998).

Não houve diferença $(\mathrm{P}>0,05)$ entre grupos genéticos quanto à porcentagem dos cortes dianteiro, paleta e acém completos, traseiro total, traseiro especial, alcatra completa e ponta-de-agulha. Esses resultados corroboram os encontrados por Gazzetta et al. (1995), que estudaram bubalinos Mediterrâneo abatidos aos 500 kg PV, e podem ser atribuídos à taxa de cresci- mento semelhante das diferentes partes do corpo (órgãos e vísceras), nos diferentes grupos genéticos.

$\mathrm{O}$ rendimento de traseiro especial dos animais deste estudo foi 2,4\% inferior ao encontrado por Vaz et al. (2003), ao trabalharem com bubalinos Mediterrâneo alimentados com volumosos à base de cana-deaçúcar ou silagem de milho.

Franzolin \& Silva (2001) encontraram, em bubalinos Mediterrâneo, rendimentos médios de dianteiro e de ponta-de-agulha 2,3\% inferior e 2,6\% superior aos obtidos nos animais deste estudo.

Na Tabela 2 encontram-se os rendimentos de carcaça e dos cortes básicos dos animais em diferentes estádios de maturidade (pesos de abate).

A maturidade (peso de abate) também não influenciou significativamente $(\mathrm{P}>0,05)$ os rendimentos de carcaça, em porcentagem do PCVZ, e os rendimentos de dianteiro, paleta completa, traseiro total, alcatra completa e coxão. Os aumentos observados com a elevação da maturidade dos animais estão de acordo com os relatos de Berg \& Butterfield (1976), que afirmam que o rendimento de carcaça se eleva com o aumento do peso do animal.

As indicações de rendimento ligeiramente superior de dianteiro e menor de traseiro em animais abatidos com 500 kg PV não atingiram significância ( $\mathrm{P}>0,05)$, sugerindo que o dimorfismo sexual típico de machos não-castrados, que traz maior desenvolvimento do dianteiro em animais adultos, ainda não havia se mani-

Tabela 1 - Percentuais médios e erros-padrão dos rendimentos de carcaça e dos cortes básicos de bubalinos de acordo com o grupo genético

Table 1 - Mean and standard errors of yields of carcass and commercial cuts from buffaloes according to genetic group

\begin{tabular}{|c|c|c|c|}
\hline \multirow{2}{*}{$\begin{array}{l}\text { Parâmetro }{ }^{1} \\
\text { Item }\end{array}$} & \multicolumn{3}{|c|}{$\begin{array}{l}\text { Grupo genético } \\
\text { Genetic group }\end{array}$} \\
\hline & Murrah & Jafarabadi & Mediterrâneo \\
\hline $\mathrm{RC}(\% \mathrm{PV})(C Y, \% B W)$ & $53,90 \pm 0,56 a$ & $54,39 \pm 0,56 a$ & $54,32 \pm 0,56 a$ \\
\hline $\mathrm{RC}(\% \mathrm{PCVZ})(C Y, \% E B W)$ & $62,60 \pm 0,48 a$ & $62,22 \pm 0,48 a$ & $63,25 \pm 0,48 a$ \\
\hline Dianteiro(Forequarter) & $41,99 \pm 0,87 a$ & $42,84 \pm 0,87 \mathrm{a}$ & $40,76 \pm 0,87 a$ \\
\hline Traseiro total (Hindquarter) & $58,01 \pm 0,87 a$ & $57,16 \pm 0,87 \mathrm{a}$ & $59,24 \pm 0,87 a$ \\
\hline Traseiro especial (Primal) & $46,00 \pm 0,74 \mathrm{a}$ & $45,40 \pm 0,74 \mathrm{a}$ & $47,73 \pm 0,74 \mathrm{a}$ \\
\hline Alcatra completa (Beef loin) & $20,12 \pm 0,37 a$ & $19,36 \pm 0,39 a$ & $19,87 \pm 0,37 \mathrm{a}$ \\
\hline Coxão (Beefround) & $25,88 \pm 0,69 a$ & $26,04 \pm 0,69 a$ & $27,86 \pm 0,69 a$ \\
\hline Ponta de agulha (Beef plate) & $12,01 \pm 0,31 \mathrm{a}$ & $11,76 \pm 0,31 \mathrm{a}$ & $11,51 \pm 0,31 \mathrm{a}$ \\
\hline
\end{tabular}

Valores seguidos pela mesma letra, na mesma linha, para grupo genético, não diferem $(P>0,05)$ pelo teste Tukey.

${ }^{1} \mathrm{RC}(\% \mathrm{PV})$ = rendimento de carcaça em relação ao peso vivo; RC (\%PCVZ) = rendimento de carcaça em relação ao peso corporal vazio; $\mathrm{PV}=$ peso vivo.

Values followed by the same letter in the same row, for genetic group do not differ $(P>0.05)$ by Tukey test.

${ }^{1} \mathrm{CY}(\% \mathrm{BW})=$ carcass yield as a function of body weight; $\mathrm{CY}(\% \mathrm{EBW})=$ carcass yield as a function of empty body weight; BW = body weight. 
Tabela 2 - Percentuais médios e erros-padrão dos rendimentos de carcaça e dos cortes básicos de bubalinos de acordo com a maturidade (peso de abate)

Table 2 - Mean and standard errors of yields of carcass and commercial cuts from buffaloes according to maturity (slaughter weight)

\begin{tabular}{lccc}
\hline & \multicolumn{3}{c}{$\begin{array}{c}\text { Maturidade (Peso de abate) } \\
\text { Maturity (Slaughter weight) }\end{array}$} \\
\cline { 2 - 4 } Parâmetro & $400 \mathrm{~kg} \mathrm{PV}$ & $450 \mathrm{~kg} \mathrm{PV}$ & $500 \mathrm{~kg} \mathrm{PV}$ \\
Item & $400 \mathrm{~kg} \mathrm{BW}$ & $450 \mathrm{~kg} \mathrm{BW}$ & $500 \mathrm{~kg} \mathrm{BW}$ \\
\hline RC (\%PV) (CY, \%BW) & $52,74 \pm 0,48 \mathrm{~b}$ & $54,30 \pm 0,49 \mathrm{ab}$ & $63,17 \pm 0,48 \mathrm{a}$ \\
RC (\%PCVZ)(CY,\%EBW) & $61,85 \pm 0,41 \mathrm{a}$ & $62,64 \pm 0,42 \mathrm{a}$ & $42,63 \pm 0,75 \mathrm{a}$ \\
Dianteiro (Forequarter) & $41,14 \pm 0,75 \mathrm{a}$ & $41,33 \pm 0,76 \mathrm{a}$ & $18,56 \pm 0,51 \mathrm{a}$ \\
Paleta completa (Shoulder clod) & $19,00 \pm 0,51 \mathrm{a}$ & $18,86 \pm 0,51 \mathrm{a}$ & $24,07 \pm 0,47 \mathrm{a}$ \\
Acém completo (Beef chuck) & $22,13 \pm 0,47 \mathrm{~b}$ & $22,47 \pm 0,48 \mathrm{~b}$ & $57,37 \pm 0,75 \mathrm{a}$ \\
Traseiro total (Hindquarter) & $58,86 \pm 0,75 \mathrm{a}$ & $58,67 \pm 0,76 \mathrm{a}$ & $44,97 \pm 0,64 \mathrm{~b}$ \\
Traseiro especial (Primal) & $47,67 \pm 0,64 \mathrm{a}$ & $46,89 \pm 0,65 \mathrm{ab}$ & $19,24 \pm 0,37 \mathrm{a}$ \\
Alcatra completa (Beefloin) & $20,20 \pm 0,37 \mathrm{a}$ & $19,97 \pm 0,37 \mathrm{a}$ & $25,73 \pm 0,60 \mathrm{a}$ \\
Coxão (Beefround) & $27,47 \pm 0,60 \mathrm{a}$ & $26,92 \pm 0,61 \mathrm{a}$ & $12,40 \pm 0,27 \mathrm{a}$ \\
Ponta de agulha (Beef plate) & $11,20 \pm 0,27 \mathrm{~b}$ & $11,78 \pm 0,27 \mathrm{ab}$ &
\end{tabular}

Valores seguidos pela mesma letra, na mesma linha, para maturidade (peso de abate), não diferem $(P>0,05)$ pelo teste Tukey.

${ }^{1} \mathrm{RC}(\% \mathrm{PV})=$ rendimento de carcaça em relação ao peso vivo; RC (\%PCVZ) = rendimento de carcaça em relação ao peso corporal vazio. $\mathrm{PV}=$ peso vivo.

Values followed by the same letter in the same row, for maturity (slaughter weight) do not differ $(P>0.05)$ by Tukey test.

${ }^{1} \mathrm{CY}(\% \mathrm{BW})=$ carcass yield as a function of body weight; $\mathrm{CY}(\% \mathrm{EBW})=$ carcass yield as a function of empty body weight; BW = body weight.

festado de forma acentuada nos animais das três raças bubalinas, apesar de estes animais terem apresentado maior $(\mathrm{P}<0,05)$ rendimento de acém. Esses resultados se assemelham aos encontrados por Estrada (1996), Jorge et al. (1997a,b) e Jorge \& Fontes (1997), que abateram bovinos Nelore com pesos semelhantes aos estabelecidos para os bubalinos deste trabalho.

O rendimento de traseiro especial foi maior $(\mathrm{P}<0,05)$ em animais abatidos aos $400 \mathrm{~kg} \mathrm{PV}$ e menor $(\mathrm{P}<0,05)$ nos abatidos aos $500 \mathrm{~kg} \mathrm{PV}$, enquanto o dos animais abatidos aos $450 \mathrm{~kg}$ PV não diferiu $(\mathrm{P}>0,05)$ dos demais. O rendimento de ponta-de-agulha, no entanto, foi maior $(\mathrm{P}<0,05)$ nos animais com $500 \mathrm{~kg}$ PV e menor naqueles com $400 \mathrm{~kg}$ PV e esses rendimentos não diferiram do obtido com peso de abate de $450 \mathrm{~kg}$. A maior proporção do traseiro especial e menor da ponta-de-agulha na carcaça de animais abatidos aos $400 \mathrm{~kg}$ PV e o inverso para animais abatidos aos $500 \mathrm{~kg}$ demonstram a tendência de animais de maior maturidade apresentarem maior proporção de corte dianteiro, que reflete em menor proporção do corte traseiro especial.

O maior rendimento de ponta-de-agulha em animais das categorias mais pesadas, ou seja, maior $(\mathrm{P}<0,05)$ em $500 \mathrm{~kg}$ PV que em $400 \mathrm{~kg}$ PV, era esperado, uma vez que as costelas mantêm seu crescimento em fases mais avançadas da vida do animal. Estes resultados estão de acordo com os encontrados por Galvão et al. (1991) e Peron et al. (1993), em bubalinos.

\section{Conclusões}

A produção de carne a partir das raças bubalinas Murrah, Jafarabadi e Mediterrâneo criadas no Brasil não difere quanto aos rendimentos de carcaça, traseiro, dianteiro e dos principais cortes básicos de interesse comercial.

A relação traseiro especial x ponta-de-agulha de bubalinos abatidos aos 400 e $500 \mathrm{~kg}$ de peso vivo necessita ser melhor estudada.

\section{Literatura Citada}

BERG, R.T.; BUTTERFIELD, R.M. New concepts of cattle growth. Sydney: Sydney University Press, 1976. 240p.

ESTRADA, L.H.C. Composição corporal e exigências de proteína, energia e macroelementos minerais (Ca, P, $\mathrm{Mg}$, Na e K), características da carcaça e desempenho do nelore e mestiços em confinamento. Viçosa, MG: Universidade Federal de Viçosa, 1996. 129p. Tese (Doutorado em Zootecnia) - Universidade Federal de Viçosa, 1996.

FRANZOLIN, R.;VELLOSO, L.; SILVA, J.R. Características da carcaça de búfalos alimentados em três níveis de energia em confinamento. In: REUNIÃO ANUAL DA SOCIEDADE BRASILEIRA DE ZOOTECNIA, 35., 1998, Botucatu, Anais... Botucatu: Sociedade Brasileira de Zootecnia, 1998, p.395-397.

FRANZOLIN, R.; SILVA, J.R. Níveis de energia na dieta para bubalinos em crescimento alimentados em confinamento. 2. Características de carcaça. Revista Brasileira de Zootecnia, v.30, n.6, p.1880-1885, 2001.

GALVÃO, J.G.; FONTES, C.A.A.; PIRES, C.C. et al. Características e composição física da carcaça de bovinos não-castrados 
de três grupos raciais, abatidos em três estádios de maturidade (estudo II). Revista da Sociedade Brasileira de Zootecnia, v.20, n.5, p.502-512, 1991.

GAZZETTA, M.C.R.R.; ITURRINO, R.P.S.; CAMPOS, B.E.S. et al. Avaliação corporal de búfalos (Bubalus bubalis) e bovinos Nelore (Bos indicus) terminados em confinamento. Boletim de Indústria Animal, v.52, n.1, p.77-86, 1995.

JORGE, A.M. Desempenho em confinamento e características de carcaça em bubalinos. In: SIMPÓSIO PAULISTA DE BUBALinOCUlturA, 1999, Jaboticabal. Anais... Jaboticabal: Funep, 1999. v.1, p. 51-67.

JORGE, A.M.; FONTES, C.A.A.; FREITAS, J.A. et al. Rendimento de carcaça e de seus cortes básicos em bovinos e bubalinos, abatidos em diferentes estádios de maturidade. Revista Brasileira de Zootecnia, v.26, n.5, p.1048-1054, 1997a.

JORGE, A.M.; FONTES, C.A.A.; SOARES, J.E. et al. Características quantitativas da carcaça de bovinos e bubalinos, abatidos em diferentes estádios de maturidade. Revista Brasileira de Zootecnia, v.26, n.5, p.1039-1047, 1997b.

JORGE, A.M.; FONTES, C.A.A. Primal cuts yield from buffalo and cattle slaughtered at different stages of maturity. In: WORLD BUFFALO CONGRESS, 5., 1997, Caserta. Proceedings... Caserta: Istituto Sperimentale per la Zootecnia, 1997, p.433-437.

LORENZONI, W.R. Estudos sobre eficiência nutritiva e qualidade da carcaça de diversos grupos de bovinos. Viçosa, MG: Universidade Federal de Viçosa, 1984. 51p. Dissertação (Mestrado em Zootecnia) - Universidade Federal de Viçosa, 1984.

MATTOS, J.C.A.; JORGE, A.M.; NOGUEIRA, J.R. Características da carcaça de búfalos Mediterrâneo (Bubalus bubalis) e bovinos Nelore (Bos indicus) terminados em confinamento. In: REUNIÃO ANUAL DA SOCIEDADE BRASILEIRA DE ZOOTECNIA, 34., 1997, Juiz de Fora. Anais... Juiz de Fora: Sociedade Brasileira de Zootecnia, 1997. p.346-348.
MÜLLER, L.; AGUIRRE, L.F.; RESTLE, J. et al. Carcass and meat quality of cattle and buffalo. In: WORLD BUFFALO CONGRESS, 4., 1994, São Paulo. Proceedings... São Paulo: Associação Brasileira de Criadores de Búfalos, 1994. p.130-132.

NATIONAL RESEARCH COUNCIL - NRC. Nutrient requeriments of beef cattle. 7.ed. Washington, D.C.:[s.n.], 1996. 243p.

PERON, A.J.; FONTES, C.A.A.; LANA, R.P. et al. Rendimento de carcaça e de seus cortes básicos e área corporal de bovinos de cinco grupos genéticos, submetidos a alimentação restrita e “ad libitum”. Revista da Sociedade Brasileira de Zootecnia, v.22, n.2, p.238-247, 1993.

STATISTICAL ANALYSIS SYSTEM. SAS User's Guide: statistics. Cary: 1994. 1014p.

VAZ, F.N.; RESTLE, J. Produção de carne com qualidade. In: RESTLE, J.; BRONDANI, I.L.; PASCOAL, L.L. et al. (Eds.) Produção intensiva com qualidade em bovinos de corte. Santa Maria: Universidade Federal de Santa Maria, 1998. p.104-119.

VAZ, F.N.; RESTLE, J.; BRONDANI, I.L. et al. Estudo da carcaça e da carne de bubalinos Mediterrâneo terminados em confinamento com diferentes fontes de volumoso Revista Brasileira de Zootecnia, v.32, n.2, p.393-404, 2003.

Recebido em: 22/09/04 Aceito em: 04/08/05 